\title{
CD26: A Prognostic Marker of Acute Lymphoblastic Leukemia in Children in the Post Remission Induction Phase
}

\author{
Atheer Awad Mehde ${ }^{1,2}$ Faridah Yusof ${ }^{1}$ Wesen Adel Mehdi ${ }^{3 *}$ Jwan Abdulmohsin \\ Zainulabdeen $^{4}$
}

\begin{abstract}
Background: ALL is an irredeemable disease due to the resistance to treatment. There are several influences which are involved in such resistance to chemotherapy, including oxidative stress as a result of the generation of reactive oxygen species (ROS) and presence of hypodiploid cells. Cluster of differentiation 26 (CD26), also known as dipeptidyl peptidase-4, is a $110 \mathrm{kDa}$, multifunctional, membrane-bound glycoprotein. Aim and objectives: The aim of this study was to evaluate the clinical significance of serum CD26 in patients with acute lymphoblastic leukaemia patients in the post remission induction phase, as well as the relationship between $\mathrm{CD} 26$ activity and the oxidative stress status. Materials and Methods: CD26, total antioxidant status (TAS), total oxidant status (TOS), and oxidative stress index (OSI), in addition to activity of related enzymes myeloperoxidase, glutathiones-transferase and xanthine oxidase, were analysed in sixty children with acute lymphoblastic leukaemia in the post remission induction phase. Results: The study showed significant elevation in CD26, TOS and OSI levels in patients with acute lymphoblastic leukaemia in the post remission induction phase in comparison to healthy control samples. In contrast, myeloperoxidase, glutathione-s-transferase and xanthine oxidase activities were decreased significantly. A significant correlation between $\mathrm{CD} 26$ concentration and some oxidative stress parameters was evident in ALL patients. Conclusions: Serum levels of CD26 appear to be useful as a new biomarker of oxidative stress in children with acute lymphoblastic leukaemia in the post remission induction phase, and levels of antioxidants must be regularly estimated during the treatment of children with ALL.
\end{abstract}

Keywords: Acute lymphoblastic leukemia (ALL) - CD26 - glutathione-s-transferase

Asian Pac J Cancer Prev, 16 (12), 5059-5062

\section{Introduction}

Acute lymphocytic leukemia (ALL) is the most common cancer in childhood, although it can also occur in adults (National Cancer Institute, 2012), The ALL occurs approximately five times more frequently than acute myeloid leukemia (Charalambous, 2012). Several age dependent host and biological features have been described (Medhe et al., 2014; Wang et al., 2014) including, differences in sensitivities of leukemic cells to corticosteroids, metabolism of chemotherapy (Kaspers et al., 1995). ALL occurs when a bone marrow cell develops errors in its DNA such as the mutations which change amino acid synthesis for the ATP synthase subunit 6 gene of mitochondrial DNA (Yacoub et al., 2014), also ,the frequency of Philadelphia chromosome abnormalities is increased with age (Shaikh et al., 2014), meanwhile the cause of ALL is not well known, a few risk factors were identified such as chemicals like hair dyes, and pesticides (Rauscher et al., 2004, Maryam et al., 2015).

CD26 or dipeptidyl peptidase- 4 is a multifunctional type II trans membrane glycoprotein expressed as a homodimer on the surface of a variety of epithelial, endothelial and lymphoid cells.CD26 interact with the extracellular matrix (Lopez-Otin and Matrisian, 2007), play important role in cell surface co receptor activity mediating viral entry (Lu et al., 2013), and regulation of intracellular signal transduction coupled to control of cell migration and proliferation (Kahne et al., 2013). Its function is needed to digest some peptides from gluten, casein and other substances that can have an opioid-like effect (Lad, 2007). In tumour performance, CD26 has an important and complex function. Its biological effect depends on the tumor type and microenvironment. CD26 is a marker of aggressive disease for certain subsets of T-cell non-Hodgkin's lymphomas/leukemias where expression of CD26 on T-lymphoblastic lymphomas/ALL cells is associated with a worse outcome compared with CD26-negative tumors (Carbone et al., 1995).

Antioxidants in biological systems can be classified on their mechanisms of action; the first one is radical scavengers that react directly with reactive oxygen species 
(ROS), inhibitors of enzyme reactions including pseudosubstrates and modifiers of the active sites of enzyme inhibitors of ROS generating enzymes, for instance, active in expression of enzyme proteins and assembly of enzyme components and inducers of anti-oxidative enzymes. Radical scavengers have been considered as promising candidates as chemopreventors because they have been found to strongly inhibit oxidative reactions both in vitro and in vivo. Therefore, dietary radical scavengers such as a-tocopherol, ascorbic acid, $\beta$-carotene and simple phenolics have attracted a great deal of attention (Huang et al., 1992). The aim of this study was to estimate of the CD26 activity in patients with acute lymphoblastic leukaemia patients at post remission induction phase, and the relationship between CD26 activity and related oxidative stress enzymes.

\section{Materials and Methods}

Blood samples of sixty child with ALL at post remission induction phase as they were submitted to the Protection of Children Hospital Medical City in Baghdad, were collected. The diagnosis for ALL founded on the following findings: leukocyte count, age, involvement of tissues other than bone marrow. Patients were compared with forty healthy control who are devoid of conditions like psychiatric disorders, diabetes mellitus, or history of any drug intake are selected as control. Five $\mathrm{ml}$ of venous blood was drawn from sixty patients of ALL with mean age $(8.34 \pm 3.33)$ years old ,after one month induction therapy treatment and normal control. Blood samples have been collected into two vacationer tubes, one containing EDTA for measurement of blood hemoglobin ( $\mathrm{Hb})$, WBC count. The blood in the second part was allowed to clot for 10-15 min. at room temperature, centrifuged for (10) min. at (3000rpm). Serum was removed for measuring of biochemical parameters. Serum CD26 level was assessed at $405 \mathrm{~nm}$ according to the Kreisel method (Kreisel W et al.,1982). TAS and TOS of serum were determined by using automated measurement methods developed by Erel method [Erel,2004,2005].OSI values were calculated according to the following formula (Kumari et al 2013): $\mathrm{Eq} . / \mathrm{L})$

OSI (A) $=$ TOS $\left(\mathrm{mmol} \mathrm{H}_{2} \mathrm{O}_{2}\right.$ Eq./L) $/$ TAS $(\mu$ mol Trolox

Myeloperoxidase (MPO) was measured by o-dianisidine as a substrate (Kumar et al., 2002). Glutathione-S-transferase (GST) was assayed using Habig WH et al method (Habig et al.,1974). Xanthine oxidoreductase activity in sera was determined as discussed by Ackermann (1974) (Ackermann, and Brill, 1974).

\section{Statistical analyses}

All statistical analyses in studies were performed using SPSS version 21.0 for Windows (Statistical Package for Social Science, Inc., USA). Expressive analysis was used to demonstrate the mean and standard deviation of variables. The significance of difference between mean values was estimated by Student T-Test. The probability $\mathrm{p}<0.05=$ significant, $\mathrm{p}>0.05=$ non-significant . Correlation analysis was used to test the linear relationship between parameters. ANOVA test was used to show the changes between variables of groups.

\section{Results}

In the current study, measurement of some clinical parameters was carried out on 60 serum specimens of children with ALL, while serum samples were collected from 40 healthy children. The host information of the studied groups is summarized in Table 1.

From the results the $\mathrm{Hb}$ concentration and PCV percentage in patients were found to be significantly decreased $(\mathrm{P}<0.01)$, when compared with that of the control, while there was a significant increase $(\mathrm{P}<0.001)$ in WBC count in patients when compared to control group.

Serum protein was significantly decreased $(\mathrm{P}<0.05)$ in patients group $(6.32 \pm 1.11 \mathrm{~g} / \mathrm{dL})$ comparing to control group (7.54 $\pm 0.56 \mathrm{~g} / \mathrm{dL}$; Table2).Serum CD26 was observed as $(85.33 \pm 0.87$, and $65.48 \pm 4.22 \mu \mathrm{mol} / \mathrm{L})$ in patients and control respectively (Table2). CD26 was significantly increased in patients than control $(\mathrm{p}<0.001$; Table 2).

TAS in patients $(1.89 \pm 0.51 \mathrm{mmol}$ Trolox Eq./L) was insignificantly decreased than in control $(2.17 \pm 0.39$ mmol Trolox Eq/L) (P>0.05; Table 2), while TOS in patients $(21.23 \pm 3.98 \mu \mathrm{mol} \mathrm{H} 2 \mathrm{O} 2 \mathrm{Eq} . / \mathrm{L})$ was significantly increased than in control $(11.33 \pm 1.57 \mu \mathrm{mol} \mathrm{H} 2 \mathrm{O} 2 \mathrm{Eq} . / \mathrm{L})$ $(\mathrm{P}<0.001$; Table 2$)$. OSI in patients $(11.23 \pm 3.26$ arbitrary unit ) was significantly increased than in control (5.22 \pm 1.88) $(\mathrm{P}<0.001$; Table 2).

Serum myeloperoxidase activity was observed as $(105.13+34.16$, and $185.44+22.12 \mathrm{U} / \mathrm{L})$ in patients and control respectively $(\mathrm{P}<0.001$; Table 2$)$.It is also clear from the result that glutathione-S-transferase activity in patients $(51.32 \pm 4.33 \mathrm{IU} / \mathrm{L})$ was significantly decreased than in control $(79.99 \pm 2.79 \mathrm{IU} / \mathrm{L})(\mathrm{P}<0.001$; Table 2$)$. Xanthine oxidase activity in patients $(11.73 \pm 4.02 \mathrm{IU} / \mathrm{L})$ was significantly decreased than in control $(18.76 \pm 1.32$ IU/L) $(\mathrm{P}<0.001$; Table 2).

Table 3 showed a significant correlation between CD26 concentration and some oxidative stress parameters (enzymatic and non enzymatic )in patients with acute lymphoblastic leukaemia patients at post remission induction phase.The results in Table 3 , it is clear that there are negative correlation between CD26 with TAS,

Table 1. Demographic and Hematological data in 60 Patients with ALL, and in 40 age- and Sex-matched Healthy Control Subjects

\begin{tabular}{lccc}
\hline Characteristic & $\begin{array}{c}\text { Patients } \\
\text { Group } \\
(\mathrm{n}=60) \\
\text { Mean } \pm \text { SD }\end{array}$ & $\begin{array}{c}\text { Healthy control } \\
\text { Subjects } \\
(\mathrm{n}=40)\end{array}$ & $\begin{array}{c}\text { P Student } \\
\text { Mean } \pm \text { SD }\end{array}$ \\
\hline Age (year) & $8.34 \pm 3.33$ & $7.60 \pm 3.33$ & $>0.05$ \\
$\mathrm{Hb}(\mathrm{g} / \mathrm{dL})$ & $9.11 \pm 1.51$ & $11.33 \pm 0.45$ & $<0.01^{\mathrm{a}}$ \\
$\mathrm{PCV} \%$ & $28.85 \pm 4.54$ & $37.09 \pm 3.10$ & $<0.01^{\mathrm{a}}$ \\
$\mathrm{WBC}^{*} 103$ & $9.96 \pm 0.33$ & $5.99 \pm 0.76$ & $<0.001^{\mathrm{a}}$ \\
\hline
\end{tabular}

${ }^{\mathrm{a}}$ Comparisons of blood concentrations of $\mathrm{Hb}, \mathrm{PCV}$, and WBC between 60 patients, and 40 age- and sex-matched healthy control subjects by Student $t$ test with $\mathrm{P}<0.05$ 
Table 2.Protein Concentration, CD26, TAS, TOS, OSI, Myeloperoxidase, Glutathione-S-Transferase and Xanthine Oxidase in the Sera Samples for ALL Group and Control Group

\begin{tabular}{lccc}
\hline Characteristic & $\begin{array}{c}\text { Patients group }(\mathrm{n}=60) \\
\text { Mean } \pm \text { SD }\end{array}$ & $\begin{array}{c}\text { Control group }(\mathrm{n}=40) \\
\text { Mean } \pm \text { SD }\end{array}$ & P Student t test \\
\hline S. Protein $(\mathrm{g} / \mathrm{dl})$ & $6.32 \pm 1.11$ & $7.54 \pm 0.56$ & $<0.05^{\mathrm{a}}$ \\
CD26 $(\mu \mathrm{mol} / \mathrm{L})$ & $85.33 \pm 0.87$ & $65.48 \pm 4.22$ & $<0.001^{\mathrm{a}}$ \\
TAS $(\mathrm{mmol}$ Trolox Eq/L) & $1.89 \pm 0.51$ & $2.17 \pm 0.39$ & $>0.05$ \\
TOS $\left(\mu \mathrm{mol} \mathrm{H}_{2} \mathrm{Eq} / \mathrm{L}\right)$ & $21.23 \pm 3.98$ & $11.33 \pm 1.57$ & $<0.001^{\mathrm{a}}$ \\
OSI (arbitrary unit) & $11.23 \pm 3.26$ & $5.22 \pm 1.88$ & $<0.001^{\mathrm{a}}$ \\
Myeloperoxidase Activity (IU/L) & $105.13+34.16$ & $185.44+22.12$ & $<0.001^{\mathrm{a}}$ \\
Glutathione-S-Transferase Activity (IU/L) & $51.32 \pm 4.33$ & $79.99 \pm 2.79$ & $<0.001^{\mathrm{a}}$ \\
Xanthine Oxidase Activity(IU/L) & $11.73 \pm 4.02$ & $18.76 \pm 1.32$ & $<0.001^{\mathrm{a}}$ \\
\hline
\end{tabular}

${ }^{a}$ Comparisons of serum concentrations of protein, CD26 level ,TOS,OSI, myeloperoxidase, glutathione-S-transferase and xanthine oxidase activities between 60 patients, and 40 age- and sex-matched healthy control subjects by Student t test with $\mathrm{P}<0.05$

Table 3. Correlation between CD26 $\mu \mathrm{mol} / \mathrm{L}$ with other Biochemical Parameters in Patients with ALL

\begin{tabular}{|c|c|c|}
\hline \multirow[t]{2}{*}{ Characteristic } & \multicolumn{2}{|c|}{$\mathrm{CD} 26 \mu \mathrm{mol} / \mathrm{L}$} \\
\hline & Pearson correlation & Sig. (2-tailed) \\
\hline TAS (mmol Trolox Eq/L) & -0.68 & 0.05 \\
\hline $\mathrm{TOS}\left(\mu \mathrm{mol} \mathrm{H} \mathrm{O}_{2}\right.$ & & \\
\hline $\mathrm{Eq} / \mathrm{L})$ & 0.77 & 0.01 \\
\hline OSI (arbitrary unit) & 0.78 & 0.01 \\
\hline $\begin{array}{l}\text { Myeloperoxidase Activity } \\
\text { (IU/L) }\end{array}$ & -0.87 & 0.01 \\
\hline Glutathione-S-Transferase & & \\
\hline Activity (IU/L) & -0.78 & 0.01 \\
\hline $\begin{array}{l}\text { Xanthine Oxidase Activity } \\
\text { (IU/L) }\end{array}$ & -0.69 & 0.05 \\
\hline
\end{tabular}

myeloperoxidase activity, glutathione-S-transferase and xanthine oxidase activity $\left(\mathrm{R}^{2}=-0.68,-0.87,-0.78\right.$ and -0.69 respectively), while there are positive correlation with the other parameters.

\section{Discussion}

The oxidant balance in leukaemia has an benefit toward ROS production. Reactive oxygen species producing complexes have the potential for significant clinical application; either by causing direct damage to cancer cells or by inhibition of growth and existence of potential cancer cells. Reactive oxygen species (ROS) are the various group of compounds which are generated by the mature myeloid lines in an innate response. ROS have an important role in intracellular signalling process. An excessive production of ROS can lead to oxidative stress in acute and chronic leukaemia but it is unclear that ROS are involved in the initiation, progression and maintenance of diseases (Hole et al., 2011). Antioxidant enzymes interact with the free radicals in different ways, by controlling the chain of reactions. We found no significant differences in TAS values between groups of patients and control,these result in agreement with the previous studies (Rybak et al., 2012). The present result showed a significant increase in TOS and OSI, while myeloperoxidase,glutathione-s-transferase, xanthine oxidase activities showed a significant decrease in in patients with ALL at post remission induction phase comparing to control, these result agreement with other studies (Morgan et al., 1981; Battisti, 2008; El-Sabagh, 2011). Hb was found significantly decreased in ALL patients compared to control. The anemia is produced by a variation of mechanisms, as well as neoplastic cell infiltration into bone marrow, also by nutritional deficiencies, and defects in erythropoietin as a result of the disease itself (Mehde et al., 2014). This finding may indicate a probable relationship between decreased $\mathrm{Hb}$ and decreased levels of myeloperoxidase activity and glutathione-s-transferase result to oxidative damage, agreement with the idea that effect of oxidative stress leading to cellular dysfunction and cell death (He et al., 2009). In leukaemia, the alteration in the oxidative balance plays a significant role in the growth, development and resistance to therapy.

The present study showed that serum CD26 was significantly increased in patients than control, also the result showed a significant correlation between CD26 concentration and some oxidative stress parameters (enzymatic and non enzymatic) in ALL patients. Serum CD26 levels are an important emerging marker of B-cell chronic lymphocytic leukaemia (Cro et al., 2009).Other study showed that the first treatment in B-CLL which display higher serum CD26 levels (Molica, 2009), CD26 serves as a marker of poor prognosis in $\mathrm{T}$ cell lymphomas CD26 (Aldinucci et al., 2004).Another study described that CD26 expression is found mainly in aggressive subtypes of non-Hodgkin's lymphomas for example T-lymphoblastic lymphoma (LBL)/T-ALL (Carbone et al., 1995). Other work also demonstrated an enhancement in the expression of CD26 in cases of T cell acute lymphoblastic leukemia, the majority of patients with T-ALL were found to express CD26 on the tumor cell surface, with a strong correlation noted between CD26 expression and the presence of DPPIV enzyme activity in the Tlymphoblasts (Klobusicka et al., 1999).

AS our knowledge no previous studied exhibited to the link between high serum CD26 levels and oxidative 
stress parameters (enzymatic and non enzymatic )has been established in ALL in children at post remission induction phase.

In conclusion, we demonstrated for the first time that an increase in serum CD26 is inversely associated with the myeloperoxidase activity, glutathione-s-transferase activity and xanthine oxidase activity , on the other hand the exact role of CD26 remains obscure, although our study was limited and preliminary character of findings, serum levels of CD26 might appear to be useful as a biomarker to detect oxidative stress status in ALL in children at post remission induction phase and levels of antioxidants must be regularly estimated during the treatment of child with ALL.

\section{References}

Ackermann E, Brill A (1974). Xanthine oxidase activity. in "methods of enzymatic analysis". Ed. Bergmeyer H.U. second Ed., Academic Press, Inc., U.S.A., pp: 521-522.

Aldinucci D, Poletto D, Lorenzon D, et al (2004). CD26 expression correlates with a reduced sensitivity to 2'-deoxycoformycin-induced growth inhibition and apoptosis in T-cell leukemia/lymphomas. Clin Cancer Res, 10, 508-20.

Battisti V, Maders L, Bagatini M, et al (2008). Measurement of oxidative stress and antioxidant status in acute lymphoblastic leukemia patients. Clin Biochem, 41, 511-8.

Carbone A, Gloghini A, Zagonel V, et al (1995) The expression of CD26 and CD40 ligand is mutually exclusive in human T-cell non-Hodgkin's lymphomas/leukemias. Blood, 86, 4617-26.

Charalambous A (2012). Risk factors for childhood leukemia: a comprehensive literature review. Health Sci J, 6, 432-68.

Childhood cancer by the ICCC. In: Howlader N, Noone AM, Krapcho M, et al (1975-2010). eds.: SEER Cancer Statistics Review, . Bethesda, Md: National Cancer Institute, based on November 2012 SEER data submission, posted to the SEER web site. Last accessed June 26, 2014.

Cro L, Morabito F, Zucal N, et al (2009). CD26 expression in mature B-cell neoplasia: its possible role as a new prognostic marker in B-CLL. Hematol Oncol, 27, 140-7.

El-Sabagh M, Ramadan K, El-slam I, IbrahimA (2011). Antioxidants status in acute lymphoblastic leukemic patients M. Am J Medicine Medical Sci, 1, 1-6.

Erel O (2005). A new automated colorimetric method for measuring total oxidant status. Clin Bio, 38, 1103-11.

Erel O (2004). A novel automated method to measure total antioxidant response against potent free radical reactions. Clin Bio, 37, 112-9.

Habig W, Pabst M, Jakoby W (1979) Glutathione-STransferase the first enzymatic step in mercapturic acid formation. $J$ Biochem, 249, 7130-9.

He J, Gu D, Wu X, et al (2005). Major causes of death among men and women in China. N Engl J Med, 353, 1124-34.

Hole P, Darley R, Tonks A (2011). Do reactive oxygen species play a role in myeloid leukemias? Blood, 117, 5816-26.

Huang M-T, Ferraro T (1992). Phenolic compounds in food and cancer prevention. in "phenolic compounds in food and their effects on health II: antioxidants and cancer prevention, Vol. 2. ACS symposium series 507' Eds Huang M-T, Ho C-T and Lee CY. Am Chem Soc, Washington, DC, pp. 8-34.

Kahne T, Lendeckel U, Wrenger S, et al (1999). Dipeptidyl peptidase IV: a cell surface peptidase involved in regulatingTcell growth (review). Int J Mol Med, 4, 3-15.

Kaspers GJ, Smets LA, Pieters R, et al (1995). Favorable prognosis of hyperdiploid common acute lymphoblastic leukemia may be explained by sensitivity to antimetabolites and other drugs: results of an in vitro study. Blood, 85, 751-6.

Klobusicka M, Babusikova O (1999). Expression of CD26 and DPP IV in T-acute lymphoblastic leukemia: comparison of immunocytochemistry with enzyme cytochemistry. Neoplasma, 46, 299-303.

Kreisel W, Heussner R, Volk B, et al (1982). Identification of the $110000 \mathrm{Mr}$. glycoprotein isolated from rat liver plasma membrane as dipeptidyl amino peptidase IV. FEBS Lett, 147, 85-8.

Kumar P, Pai PH, Saundar S (2002). NADH-Oxidase and myeloperoxidase activity of visceral leishmanaisis patients. $J$ Med Microbiol, 51, 832-6.

Kumari S, Verma A, Rungta S, et al (2013). Serum prolidase activity, oxidant and anti-oxidant status in non-ulcer dyspepsia and healthy volunteers. ISRN Biochemistry, 182601, 6-9.

Lad MM (2007). Biomedical approach for autism -basics- defeat autism now (DAN) model. [DETAIL]

Lopez-Otin C, Matrisian L (2007). Emerging roles of proteases in tumour suppression. Nat Rev Cancer, 7, 800-8.

Lu G, Hu Y, Wang Q, et al (2013). Molecular basis of binding between novel human coronavirus MERS-CoV and its receptor CD26. Nature, 500, 227-231.

Maryam Z, Sajad A, Maral N, et al (2015). Relationship between exposure to pesticides and occurrence of acute leukemia in Iran. Asian Pac J Cancer Prev, 16, 1, 239-244.

Mehde A, Mehdi W, Zainulabdeen J, Abdulbari A (2014). Correlation of inhibin and several antioxidants in children with acute lymphoblastic leukemia. Asian Pac J Cancer Prev, 15, 4843-6.

Molica S, Digiesi G, Mirabelli R, et al (2009). Serum level of CD26 predicts time to first treatment in early B-chronic lymphocytic leukemia. Eur J Haematol, 83, 208-14.

Morgan E, Honig G, Nelson DJ (1981). Acute lymphocytic leukemia in a child with congenital xanthine oxidase deficiency: implications for therapy. Am J Pediatr Hematol Oncol, 3, 439-41.

Rauscher GH, Shore D, Sandler DP (2004). Hair dye use and risk of adult acute leukemia. Am J Epidemiol, 160, 19-25.

RybakM, PanasiukA, Czygier M, et al (2012). Total antioxidant status (TAS) in childhood cancer survivors. Folia Histochemica Et Cytobiologica, 50, 468-72.

ShaikhM, AdilS, Shaikh M, Khurshid M (2014). Frequency of chromosomal abnormalities in pakistani adults with acute lymphoblastic leukemia. Asian Pac J Cancer Prev, 15, 9495-8.

Wang C-X, Wang X, Liu H-B, et al (2014). Aberrant DNA methylation and epigenetic inactivation of hMSH2 decrease overall survival of ALL patients via modulating cell cycle and apoptosis. Asian Pac J Cancer Prev, 15, 355-62.

Yacoub H, Mahmoud W, Alaa-Eldeen H, et al (2014). New haplotypes of the ATP synthase subunit 6 gene of mitochondrial DNA are associated with acute lymphoblastic leukemia in Saudi Arabia. Asian Pac J Cancer Prev, 15, 10433-8. 